\title{
Insight into blood pressure targets for universal coverage of hypertension services in Iran: the 2017 ACC/AHA versus JNC 8 hypertension guidelines
}

Mahdi Mahdavi ${ }^{1,2}$, Mahboubeh Parsaeian³, Bahram Mohajer ${ }^{4}$, Mitra Modirian ${ }^{4}$, Naser Ahmadi ${ }^{4}$, Moein Yoosefi ${ }^{4}$, Parinaz Mehdipour ${ }^{4}$, Shirin Djalalinia ${ }^{5}$, Nazila Rezaei ${ }^{4}$, Rosa Haghshenas ${ }^{4,6}$, Forough Pazhuheian ${ }^{4}$, Zahra Madadi ${ }^{4}$, Mahdi Sabooni ${ }^{7}$, Farideh Razi ${ }^{8}$, Siamak Mirab Samiee ${ }^{7}$ and Farshad Farzadfar ${ }^{4,6^{*}}$ (D)

\begin{abstract}
Background: We compared the prevalence, awareness, treatment, and control of hypertension in Iran based on two hypertension guidelines; the 2017 ACC/AHA - with an aggressive blood pressure target of 130/80 mmHg- and the commonly used JNC8 guideline cut-off of 140/90 mmHg. We shed light on the implications of the 2017 ACC/AHA for population subgroups and high-risk individuals who were eligible for non-pharmacologic and pharmacologic therapies.

Methods: Data was obtained from the Iran national STEPS 2016 study. Participants included 27,738 adults aged $\geq 25$ years as a representative sample of Iranians. Regression models of survey design were used to examine the determinants of prevalence, awareness, treatment, and control of hypertension.

Results: The prevalence of hypertension based on JNC8 was 29.9\% (95\% Cl: 29.2-30.6), which soared to 53.7\% (52.9-54.4) based on the 2017 ACC/AHA. The percentage of awareness, treatment, and control were 59.2\% (58.0-60.3), 80.2\% (78.981.4), and 39.1\% (37.4-40.7) based on JNC8, which dropped to 37.1\% (36.2-38.0), 71.3\% (69.9-72.7), and 19.6\% (18.3-21.0), respectively, by applying the 2017 ACC/AHA. Based on the new guideline, adults aged 25-34 years had the largest increase in prevalence (from 7.3 to 30.7\%). They also had the lowest awareness and treatment rate, contrary to the highest control rate (36.5\%) between age groups. Compared with JNC8, based on the 2017 ACC/AHA, 24, 15, 17, and $11 \%$ more individuals with dyslipidaemia, high triglycerides, diabetes, and cardiovascular disease events, respectively, fell into the hypertensive category. Yet, based on the 2017 ACC/AHA, 68.2\% of individuals falling into the hypertensive category were eligible for receiving pharmacologic therapy (versus $95.7 \%$ in JNC8). LDL cholesterol $<130 \mathrm{mg} / \mathrm{dL}$, sufficient physical activity (Metabolic Equivalents $\geq 600$ /week), and Body Mass Index were found to change blood pressure by $-3.56(-4.38,-2.74),-2.04(-2.58,-1.50)$, and $0.48(0.42,0.53) \mathrm{mmHg}$, respectively.

(Continued on next page)
\end{abstract}

\footnotetext{
*Correspondence: farzadfar3@yahoo.com

${ }^{4}$ Non-Communicable Diseases Research Center, Endocrinology and

Metabolism Population Sciences Institute, Tehran University of Medical Sciences, Tehran, Iran

${ }^{6}$ Endocrinology and Metabolism Research Center, Endocrinology and

Metabolism Clinical Sciences Institute, Tehran University of Medical Sciences,

Tehran, Iran

Full list of author information is available at the end of the article
}

(c) The Author(s). 2020 Open Access This article is licensed under a Creative Commons Attribution 4.0 International License, which permits use, sharing, adaptation, distribution and reproduction in any medium or format, as long as you give appropriate credit to the original author(s) and the source, provide a link to the Creative Commons licence, and indicate if changes were made. The images or other third party material in this article are included in the article's Creative Commons licence, unless indicated otherwise in a credit line to the material. If material is not included in the article's Creative Commons licence and your intended use is not permitted by statutory regulation or exceeds the permitted use, you will need to obtain permission directly from the copyright holder. To view a copy of this licence, visit http://creativecommons.org/licenses/by/4.0/ The Creative Commons Public Domain Dedication waiver (http://creativecommons.org/publicdomain/zero/1.0/) applies to the data made available in this article, unless otherwise stated in a credit line to the data. 
(Continued from previous page)

Conclusions: Switching from JNC8 to 2017 ACC/AHA sharply increased the prevalence and drastically decreased the awareness, treatment, and control in Iran. Based on the 2017 ACC/AHA, more young adults and those with chronic comorbidities fell into the hypertensive category; these individuals might benefit from earlier interventions such as lifestyle modifications. The low control rate among individuals receiving treatment warrants a critical review of hypertension services.

Keywords: Hypertension, JNC8 hypertension guideline, 2017 ACC/AHA hypertension guideline, Effective coverage, Prevalence, Awareness, Treatment, Control, Iran

\section{Background}

Hypertension (HTN) is the leading modifiable risk factor for premature morbidity and mortality in the world and Iran. The prevalence of HTN is rising globally [1]. In 2000, 26.4\% of the world's adults had HTN, which is expected to reach $29.2 \%$ by 2025 [2]. Among Iranians aged 25-70 years, $24.1 \%$ were living with HTN in 2011 [3]. The fact that a large proportion of the population is living with HTN and its costly comorbidities make it a health priority and a tracer for measuring progress towards Universal Health Coverage (UHC).

The definition of hypertension, which determines a cutoff for hypertension diagnosis, directly affects the estimates made for the UHC of hypertension i.e. prevalence, awareness, treatment and control, and subsequently, the treatment costs incurred by health systems for hypertension control. Following the release of the 2017 ACC/AHA Guideline for the Prevention, Detection, Evaluation, and Management of High Blood Pressure in Adults with the cut-off of $130 / 80 \mathrm{mmHg}$ [4], a reasonable blood pressure (BP) target for the effective coverage of hypertension has become a heated debate [5]. For several years, guidelines such as the JNC8 (with $140 / 90 \mathrm{mmHg}$ as its cut-off for hypertension) were used to determine the prevalence, awareness, treatment, and control of hypertension [6].

Studies have shown that switching from JNC8 to the 2017 ACC/AHA increases the prevalence of hypertension $[7,8]$. However, evidence on the implications of the 2017 ACC/AHA guideline on the awareness, treatment, and control of hypertension is under-developed [9]. Despite the potential health benefits of the 2017 ACC/AHA guideline $[7,8]$, adopting this guideline to enhance hypertension control in low- and middle- income countries (LMICs) is under question - given its economic impacts [10]. According to Watkins, the burden of the possibly higher numbers of individuals that shift from the 'elevated' and 'prehypertensive' into the 'hypertensive' categories (based on the 2017 ACC/AHA guideline) is hardly bearable by the already-overburdened health systems of LMICs [11]. This counterargument warrants more empirical findings per country in order to estimate the burden of embarking on the 2017 ACC/AHA hypertension guideline.
In this study, we estimated the prevalence, awareness, treatment, and control of HTN, based on the two 'JNC8' and '2017 ACC/AHA' guidelines. We shed light on the implications (and benefits) of adopting an intensified blood pressure control recommended by the $2017 \mathrm{ACC} /$ AHA, for different subgroups of Iranian populations and high-risk hypertensive adults using the 10-year atherosclerotic cardiovascular disease (ASCVD) risk score. We compared the proportion of hypertensive individuals eligible for pharmacologic therapy based on both guidelines and discussed the implications in terms of the potential costs imposed on the Iranian health system to provide treatment to adults eligible for pharmacologic therapy.

\section{Methods \\ Research design}

We used the data collected in the 'Iran STEPS 2016' study. The WHO STEPwise approach to Surveillance (STEPS) provided the grounds for conducting the Iran STEPS 2016 study [12]. The Iran STEPS 2016 study included a representative sample of the Iranian population from urban and rural areas of 30 provinces, which were selected based on a multistage random sampling method. All Iranians aged $>18$ years who were living in Iran at the time of data collection were eligible for inclusion in the study. The original study questionnaire was constructed by the WHO STEPS. It was translated into Persian and was culturally adapted through learning from the application of the questionnaire in the earlier STEPS studies conducted in 2005, 2006, 2007, 2008, 2009, and 2011. During this development process, the consistency, validity, and reliability of the questionnaire were assessed. Data was collected by trained interviewers through in-person interviews. The methods employed in the Iran STEPS 2016 study which include details on the sampling design, the validity and reliability of the study questionnaire, the interview guide, and data collection methods are presented elsewhere [13]. The interview guide was not developed for the present study, but for the Iran STEPS 2016 study. 


\section{Measures \\ Outcome definitions}

The main outcomes consisted of prevalence, awareness, treatment, and control of HTN. We distinguished hypertension based on the JNC8 and the 2017 ACC/AHA guidelines. Based on JNC8, we considered individuals with systolic blood pressure (SBP) $\geq 140 \mathrm{mmHg}$ or diastolic blood pressure (DBP) $\geq 90 \mathrm{mmHg}$ as hypertensive; whereas, based on 2017 ACC/AHA, those with SBP $\geq 130 \mathrm{mmHg}$ or $\mathrm{DBP} \geq 80$ $\mathrm{mmHg}$ [4] were considered hypertensive. Furthermore, the self-reported use of antihypertensive drugs in the last 2 weeks was considered as the presence of HTN for both definitions [14]. According to the WHO STEPS manual, trained personnel measured blood pressure on the right upper-arm three times, having had the participant rest for $5 \mathrm{~min}$ in a seated position [12]. An average of the last two measurements was considered as the blood pressure measure. Awareness was deemed to be present if an individual answered 'Yes' to the question 'Have you ever been diagnosed with hypertension by a physician or a health professional?' Treatment was defined as the self-reported use of antihypertensive drugs among aware individuals. Hypertension control referred to an average $\mathrm{SBP}<130 \& \mathrm{DBP}<80 \mathrm{mmHg}$ based on the 2017 ACC/AHA and an average SBP $<140$ \& DBP $<90 \mathrm{mmHg}$ based on the JNC8.

\section{Covariates}

Covariates included demographic, socio-economic status (SES), lifestyle, health insurance coverage, and cardiovascular disease (CVD) risk factors. Demographic factors included age, gender, marital status, and place of residence. Age groups consisted of 25-34, 35-44, 45-54, 55-64, 65-74, and 75+ years. Marital status included two groups; single/divorced/widow and married. SES comprised of wealth status and the years of schooling. Wealth status was measured by the wealth index [15] and was grouped into the poorest, poor, average, rich, and richest. Based on the years of schooling, participants were categorized into four groups; participants with no schooling, 1-6 years, 7-12 years, and higher than 12 years of schooling. Insurance coverage referred to basic and complementary health insurance. Basic health insurance refers to a minimum coverage of essential health services by public health insurance organizations. Complementary health insurance is a coverage policy provided by private insurers that pays for surcharges of medical services not covered by basic health insurance or services delivered by private providers [16].

Lifestyle factors consisted of smoking, alcohol consumption, intake of fruits and vegetables, salt intake, and physical activity. Smoking has a dichotomy of statuses: neversmoker/non-smoker and current daily cigarette smoker. Smoker referred to a person who smoked cigarettes on a daily basis at the time of the survey. Never-smoker/non- smoker referred to a person who had never smoked or had quitted smoking. Since evidence on the relationships between smoking and hypertension is controversial, we relied on [17] comparing the outcomes between former-smokers and never-smokers versus current-smokers. Furthermore, only $70(0.26 \%)$ study participants reported using tobacco products other than cigarettes; whereas, 2911 (10.72\%) study participants reported that they were current cigarette smokers. Consequently, smoking other tobacco products was not included in the analysis and our analysis focused on cigarette smoking. In terms of alcohol intake, we classified the participants into alcohol drinkers and nondrinkers. An alcohol drinker referred to a person who had consumed any type of alcohol product during the last 12 months before the time of the survey, regardless of the duration or frequency of consumption. Non-drinker referred to a participant who had consumed no alcohol during the same period of time. The intake of fruits and vegetables was estimated for $24 \mathrm{~h}$ (24-h). We considered five portions of fruits and vegetables, consisting of two portions of fruits and three portions of vegetables, as a sufficient daily intake based on the dietary guidelines [18]. One portion of fruits referred to $80 \mathrm{~g}$ of fruits. In order to make the portion size comprehensible to the study participants, 'one mediumsized fruit, like a medium-sized apple, or $14^{\text {th }}$ of a cup of dried fruits' was considered one portion of fruits. One portion of vegetables equalled 'one cup of raw leafy vegetables, like spinach, or half a cup of cooked vegetables'.

The 24-h salt intake was estimated from spot-urine samples using the Tanaka equation [19]:

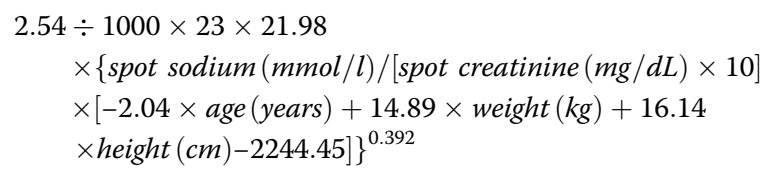

All spot urine samples were collected in the morning between 8.00-10.00 a.m., and transferred to a central laboratory unit according to the 2016 STEPS study protocol [13]. The detailed methods and results of applying the Tanaka equation to the Iran STEPS 2016 data have been published elsewhere [20]. We analysed the relationships between salt intake and outcomes using salt intake as a continuous and dichotomized variable. Since only $2 \%$ of the study sample had a salt intake of $<5 \mathrm{~g} /$ day, we considered $10 \mathrm{~g} /$ day as the cut-off. The complementary analysis of relationships between daily salt intake and blood pressure among hypertensive, aware, treatment-receiving, and under-control individuals is presented in Additional File 1. Physical activity was measured using the WHO Global Physical Activity Questionnaire (GPAQ) version 2 with a cut-off of metabolic equivalents (METs) $\geq 600$ /week as sufficient [21]. Body Mass Index (BMI) had four levels; 
underweight $\left(<18.5 \mathrm{~kg} / \mathrm{m}^{2}\right)$, normal $\left(18.5-24.9 \mathrm{~km} / \mathrm{m}^{2}\right)$, overweight $\left(25.0-29.9 \mathrm{~kg} / \mathrm{m}^{2}\right)$, and obesity $\left(\geq 30 \mathrm{~kg} / \mathrm{m}^{2}\right)$. CVD risk factors consisted of dyslipidaemia, high triglycerides, diabetes mellitus (DM), and self-reported history of CVDs, i.e. myocardial infarction and/or stroke [4]. Dyslipidaemia referred to either total cholesterol $\geq 200 \mathrm{mg} / \mathrm{dL}$, high-density lipoprotein (HDL) cholesterol $<35 \mathrm{mg} / \mathrm{dL}$, or low-density lipoprotein (LDL) cholesterol $\geq 130 \mathrm{mg} / \mathrm{dL}$. High triglycerides referred to fasting triglycerides $\geq 200$ $\mathrm{mg} / \mathrm{dL}$ [22]. DM referred to $\mathrm{HbA} 1 \mathrm{c}>48 \mathrm{mmol} / \mathrm{mol}$ or fasting blood sugar $(\mathrm{FBS})>126 \mathrm{mg} / \mathrm{dL}$ or self-reported DM [23].

\section{Statistical analysis}

We calculated the ratio and 95\% confidence interval (95\% CI) of prevalence, awareness, treatment, and control based on cut-offs recommended by the JNC8 and 2017 ACC/ AHA. We constructed univariate and multiple logistic regression models to account for the effects of covariates on prevalence, awareness, treatment, and control based on the 2017 ACC/AHA only. We calculated the number and percentage of individuals eligible for pharmacologic therapy based on both JNC8 [6] and the 2017 ACC/AHA. The number of individuals eligible for nonpharmacologic therapy was only determined based on the 2017 ACC/AHA, which comprised elevated, HTN stage 1, and HTN stage 2 adults. Based on 2017 ACC/AHA, two groups were eligible for pharmacologic therapy: a) individuals with $\mathrm{BP}$ $\geq 140 / 90$, and b) those with $\mathrm{BP} \geq 130 / 80$ who had 10 -year atherosclerotic CVD (ASCVD) risk $\geq 10 \%$. The number of adults eligible for pharmacologic therapy was also determined based on JNC8 [6]. Among individuals with BP $\geq 120 / 80 \mathrm{mmHg}$, associations between blood pressure and lifestyle factors, weight, BMI, physical activity, intake of fruits and vegetables, 24-h intake of salt, LDL cholesterol, and alcohol consumption were tested.

Given the multistage clustering structure, a complex survey analysis was used to obtain summary measures and statistical models. We weighted samples according to the 2015 Iranian National Population Census. Logistic regression models with a survey design was used to analyse associations between the outcomes and covariates. We analysed the data using Stata 13 and R 3.4.1 statistical software programs.

\section{Results}

The study sample included 27,738 participants who were aged $\geq 25$ years. Of these, 573 (2\%) were excluded from the analyses due to missing values of SBP or DBP measurements. In the end, 27,165 participants were considered for analysis, of whom about $70 \%$ were between 25 and 54 years old.

We found that adopting 2017 ACC/AHA markedly increased the prevalence. Based on JNC8, the prevalence was
29.9\% (95\% CI: 29.2-30.6), which soared to 53.7\% (52.954.4), based on the 2017 ACC/AHA (Table S1). Likewise, the prevalence rate sharply increased by age from younger to older groups, reaching its peak at $82.4 \%$ among those $\geq 75$ years old (Odds Ratio (OR): 7.97 [6.29-10.10]) (Table S1). Based on the 2017 ACC/AHA, the largest increase in prevalence was observed in the 25-34-year-old age group; the prevalence increased from $7.3 \%$ based on JNC8 to $30.7 \%$ based on the 2017 ACC/AHA.

The prevalence percentage was lower among females (OR: 0.74 [0.67-0.82]) and rural dwellers (OR: 0.90 [0.80$1.00])$. Among the wealth groups, the richest group had the lowest prevalence (OR: 0.69 [0.58-0.82]). The prevalence also significantly decreased from $73.7 \%$ among illiterates to $44.2 \%$ among those with $>12$ years of schooling (OR: 0.66 [0.55-0.79]). Prevalence significantly increased from normal BMI to overweight (OR: 1.60 [1.44-1.78]) and obese (OR: 2.22 [1.97-2.51]). It was significantly higher among those with dyslipidaemia (OR: 1.15 [1.051.26]), high triglycerides (OR: 1.31 [1.15-1.49]), DM (OR: 1.58 [1.37-1.82]), and CVD history (OR: 1.77 [1.28-2.45]). By lowering the blood pressure cut-off point by $10 \mathrm{mmHg}$ to $130 / 80 \mathrm{mmHg}, 24,15,17$, and $11 \%$ more individuals with dyslipidaemia, high triglycerides, diabetes, and CVD events, respectively, fell into the hypertensive category. For instance, based on the JNC $8,71.5 \%$ of individuals with previous CVD events were considered hypertensive, which increased to $82.5 \%$ based on the 2017 ACC/AHA (Table S1).

Based on the JNC8, 59.2\% (58.0-60.3) of hypertensive individuals were aware; whereas, according to the 2017 ACC/AHA, 37.1\% (36.2-38.0) were aware (Table S2). Based on the 2017 ACC/AHA guideline, awareness significantly increased by age, from $9.7 \%$ in the youngest to $67.9 \%$ in the oldest group (OR: 13.23 [9.54-18.37]). A larger proportion of females $(45.1 \%)$ were aware (OR: 1.59 [1.39-1.81]) compared to males (28.9\%). Awareness declined with increases in years of schooling, reaching its lowest among the well-educated group (OR: 0.58 [0.46-0.73]). Patients with a higher awareness were more likely to have complementary insurance coverage.

Awareness was significantly higher among the overweight (OR: 1.39 [1.19-1.62]) and obese (OR: 1.71 [1.442.03]) groups. Individuals with salt $\geq 10 \mathrm{~g} /$ day were less likely to be aware (OR: 0.87 [0.77-0.98]) and one gram/day salt decreased the odds of awareness (OR: 0.96 [0.94-0.99]) (see also Additional File 1). Awareness was significantly higher among individuals with DM (OR: 1.76 [1.52-2.05]) and a history of CVD (OR: 2.51 [1.79-3.52]).

Based on the JNC8, 80.2\% (78.9-81.4) of hypertensive individuals were receiving treatment, which decreased to 71.3\% (69.9-72.7) when the 2017 ACC/AHA guideline was considered (Table S3). Based on the 2017 ACC/AHA, the ratio of treatment-receiving individuals increased by 
age (Table S3). The ORs of treatment increased from 2.83 (1.56-5.17) among the 35-44-year-old age group to 13.38 (6.83-26.24) among those $\geq 75$ years old. Treatment percentage increased with insufficient physical activity (OR: 1.21 [1.00-1.47]). Diabetics were more likely than nondiabetics to have received more treatment (OR: 1.79 [1.43-2.24]). Naturally, $92.2 \%$ of patients with CVD history were receiving treatment (OR: 3.02 [1.79-5.11]).

The control rate of HTN was 39.1\% (37.4-40.7) based on the JNC8. It dropped to $19.6 \%(18.3-21.0)$ based on the 2017 ACC/AHA (Table S4). Control significantly decreased from $36.5 \%$ among the 25-34-year-old age group (Table S4) to $17.1 \%$ among the 55-64-year-old age group (OR: 0.27 [0.09-0.79]). Subsequently, control insignificantly increased among individuals older than 65 years. Control was significantly associated with complementary health insurance coverage (OR: 1.40 [1.061.86]). In terms of lifestyle factors, individuals with a lower control were more likely to be obese (OR: 0.56 [0.38-0.82]). Having a CVD history significantly increased HTN control (OR: 2.06 [1.35-3.14]).

Based on the 2017 ACC/AHA, $68.2 \%$ of the hypertensive individuals or $37.2 \%$ of the entire sample had either $\mathrm{BP} \geq 140 / 90$ or $\mathrm{BP} \geq 130 / 80$ with 10 -year ASCVD risk $\geq 10 \%$, thus were eligible for pharmacologic therapy. Whereas, based on JNC8, 95.7\% of hypertensive individuals and $28.6 \%$ of the entire sample were eligible for pharmacologic therapy (Table 1). We also found that among participants with $\mathrm{BP}>120 / 80 \mathrm{mmHg}, 97.9 \%$ were eligible to reduce their salt intake to $<5 \mathrm{~g} /$ day, $89.6 \%$ consumed insufficient amounts of fruits and vegetables, $69.4 \%$ were overweight or obese, and $57.2 \%$ were physically inactive.

The effects of lifestyle factors on SBP among adults eligible for pharmacologic and non-pharmacologic therapy are presented in Table 2. LDL cholesterol $<130 \mathrm{mg} / \mathrm{dL}$ had a large effect size, $-3.56(-4.38,-2.74) \mathrm{mmHg}$. Just one unit increase in BMI increased SBP by $0.48(0.42$, $0.53) \mathrm{mmHg}$. Being physically active significantly lowered SBP $(-2.04(-2.58,-1.50)) \mathrm{mmHg}$. The effect sizes of sufficient intake of fruits and vegetables and salt intake $\geq 10$ g/day were $-1.67(-2.49,-0.86)$ and $1.52(0.90,2.13)$ $\mathrm{mmHg}$, respectively.

\section{Discussion}

Switching from JNC8 to the 2017 ACC/AHA created a sharp rise in the prevalence and a drastic decline in awareness, treatment, and control of HTN. Based on the 2017 ACC/AHA, half of the study samples fell into the hypertensive category. Two-thirds of adults in the hypertensive category were unaware, indicating that they were undiagnosed. About one-third of those with awareness remained untreated, and among those treated, less than $20 \%$ were under control.
Table 1 Frequency and proportion of participants eligible for pharmacologic and nonpharmacologic therapy*

\begin{tabular}{|c|c|c|c|}
\hline Type of therapy & $\%$ & No. & $\begin{array}{l}\text { Sample } \\
\text { analysed }\end{array}$ \\
\hline \multicolumn{4}{|l|}{$\begin{array}{l}\text { Eligible for pharmacologic } \\
\text { therapy based on } 2017 \\
\text { ACC/AHA }\end{array}$} \\
\hline Among samples & $37.2(36.2-38.2)$ & 9746 & 26,718 \\
\hline Among hypertensive patients & $68.2(66.9-69.5)$ & 9746 & 14,147 \\
\hline \multicolumn{4}{|l|}{$\begin{array}{l}\text { Eligible for pharmacologic } \\
\text { therapy based on JNC8 }\end{array}$} \\
\hline Among samples & $28.6(28.0-29.3)$ & 7805 & 27,165 \\
\hline Among hypertensive patients & $95.7(95.2-96.1)$ & 7805 & 8148 \\
\hline \multicolumn{4}{|l|}{$\begin{array}{l}\text { Nonpharmacologic } \\
\text { therapy }\end{array}$} \\
\hline $\begin{array}{l}\text { Being overweight } \\
\text { or obese }\end{array}$ & $69.4(68.6-70.2)$ & 11,809 & 17,028 \\
\hline $\begin{array}{l}\text { Insufficient intake of } \\
\text { fruits } \& \text { vegetables } \\
\text { (fruits }<2 \text { portions } \& \\
\text { vegetables }<3 \text { portions) }\end{array}$ & $89.6(88.9-90.3)$ & 15,527 & 17,344 \\
\hline Salt Intake $>5 \mathrm{~g} /$ day & $97.9(97.6-98.3)$ & 11,718 & 11,950 \\
\hline Salt Intake > $10 \mathrm{~g} /$ day ${ }^{* *}$ & $42.5(41.4-43.7)$ & 5208 & 11,950 \\
\hline $\begin{array}{l}\text { Low physical activity } \\
\text { (METs }<600 / \text { week) }\end{array}$ & $57.2(56.3-58.2)$ & 8958 & 15,721 \\
\hline $\begin{array}{l}\text { LDL Cholesterol } \geq 130 \\
\mathrm{mg} / \mathrm{dL}\end{array}$ & $16.1(15.3-16.9)$ & 1989 & 12,248 \\
\hline
\end{tabular}

*Nonpharmacologic therapy is recommended for all individuals with SBP $\geq 120 \mathrm{mmHg}$ or DBP $>80 \mathrm{mmHg}$ (individuals with elevated, stage 1, and stage 2 hypertension) based on 2017 ACA/AHA

** Since less than $5 \%$ of study samples had a salt intake of less than $5 \mathrm{~g} /$ day, we considered $10 \mathrm{~g} /$ day as the cut-off for the analysis of salt intake

The increase in prevalence upon using the $2017 \mathrm{ACC} /$ AHA guideline in Iran is consistent with a similar increase in prevalence upon using this guideline in other countries e.g. Nepal [21], China [9], and the United States $[24,25]$. By adopting the new guideline, the largest increase in prevalence was observed among young and middle-aged individuals, which has also been reported in China [9].

The prevalence and awareness of hypertension in Iran (compared based on the cut-off of $140 / 90 \mathrm{mmHg}$ ) resemble findings reported in other middle-income countries [26, 27]. Despite a higher treatment rate in Iran, the control rate stood at $39.1 \%$, which is yet noticeably lower than Turkey, with 53.9\% in 2012, and Lebanon, with $54 \%$ in 2014 [28].

Increases in age significantly increased prevalence, awareness, and treatment but decreased the control rate. The likelihood of an increase in prevalence grew by a higher BMI (overweight and obese), higher triglycerides, dyslipidaemia, diabetes, and previous CVD history. Studies also reported a higher prevalence among the overweight, obese $[29,30]$, diabetics, and those with a history of CVD [31]. Higher awareness and treatment rates were also observed 
Table 2 Predicting factors of blood pressure among participants eligible for pharmacologic and nonpharmacologic therapy

\begin{tabular}{|c|c|c|c|}
\hline Lifestyle characteristics & Beta (effect size) & $95 \% \mathrm{Cl}$ & $P$ value \\
\hline$\overline{\text { Weight }(\mathrm{kg})}$ & $0.003^{*}$ & $-0.02,0.02$ & 0.725 \\
\hline BMI $\left(\mathrm{kg} / \mathrm{m}^{2}\right)$ & 0.48 & $0.42,0.53$ & $<0.001$ \\
\hline $\begin{array}{l}\text { Sufficient physical } \\
\text { activity }^{\dagger}\end{array}$ & -2.04 & $-2.58,-1.50$ & $<0.001$ \\
\hline $\begin{array}{l}\text { Intake of fruits \& } \\
\text { vegetables }{ }^{\ddagger}\end{array}$ & -1.67 & $-2.49,-0.86$ & $<0.001$ \\
\hline Salt intake ${ }^{\S}$ & 1.52 & $0.90-2.13$ & $<0.001$ \\
\hline $\begin{array}{l}\text { LDL Cholesterol < } 130 \\
\mathrm{mg} / \mathrm{dL} \|\end{array}$ & -3.56 & $-4.38,-2.74$ & $<0.001$ \\
\hline Alcohol consumption ${ }^{\#}$ & 2.69 & $1.71,3.66$ & $<0.001$ \\
\hline
\end{tabular}

*This is the only figure with three decimals in this table

${ }^{\dagger}$ Individuals with sufficient Physical activity (PA) (METs $\geq 600 /$ week) were compared against those with insufficient PA (METs $<600 /$ week)

${ }^{\ddagger}$ Intake of fruits and vegetables was compared between those who consumed sufficient (fruits $\geq 2$ portions $\&$ vegetables $\geq 3$ portions) and insufficient portions of fruits and vegetables (fruits $<2$ portions $\&$ vegetables $<3$ portions) in $24 \mathrm{~h}$

\$Individuals with a salt intake of $\geq 10 \mathrm{~g} /$ day in $24 \mathrm{~h}$ were compared against those with an intake of $<10 \mathrm{~g} /$ day

"Individuals with $\mathrm{LDL}$ cholesterol< $130 \mathrm{mg} / \mathrm{dL}$ were compared against those with $\mathrm{LDL}$ cholesterol $\geq 130 \mathrm{mg} / \mathrm{dL}$

\#Non-drinker individuals were compared against drinkers

among those with comorbidities of diabetes and CVD [31]. This indicates a higher likelihood of diagnosis and treatment in individuals living with such comorbidities.

Based on the 2017 ACC/AHA, a larger ratio of comorbid patients fell into the hypertensive category $(24,15,17$, and $11 \%$ more individuals with dyslipidaemia, high triglycerides, diabetes, and CVD events, respectively). Under this guideline, many high-risk adults might be covered by pharmacologic therapies and be protected against the progression of CVD and diabetic renal diseases [5, 32].

Based on the 2017 ACC/AHA, the proportion of participants with $\mathrm{BP}>120 / 80 \mathrm{mmHg}$ who were eligible for nonpharmacologic therapy was high. $97.9 \%$ of participants with $\mathrm{BP}>120 / 80 \mathrm{mmHg}$ need to lower their salt intake to $<5 \mathrm{~g} /$ day as recommended by the WHO [33]; $89.6 \%$ need to consume sufficient fruits and vegetables, and $69.4 \%$ need to lose extra weight.

Though the Tanaka formula provided statistically better estimates for sodium intake in Iran [20], all three common formulas used to estimate sodium intake (Kawasaki, Tanaka, and INTERSALT) were systematically biased with overestimation at lower levels and underestimation at higher levels of sodium intake [34]. In the light of this evidence, we noted that the level of salt intake in Iran was much higher than the $5 \mathrm{~g} /$ day cut-off recommended by $\mathrm{WHO}$, therefore even in the presence of underestimation of sodium intake calculation, sodium intake levels exceeded the recommended salt intake level. Thus, the percentage of those eligible for reducing salt intake remained quite large.
Lifestyle factors, LDL cholesterol, physical activity, and BMI had large effect sizes on lowering BP. Based on these findings, non-pharmacologic therapy in hypertensive patients may be considered to modify these lifestyle factors. The modification of these lifestyle factors could be a recommended therapy for low risk adults (ASCVD $<10 \%)$ who fall into the hypertensive category under the new guideline.

We contribute to a better understanding of the burden of hypertension based on two distinctive guidelines. Considering the more aggressive cut-off point of 130/90 $\mathrm{mmHg}$ resulted in a greater prevalence and lower effective coverage of hypertension. The largest increase in prevalence was observed in adults aged 25-34 years. Given the large population of this age group (16.8 million) in Iran, the number of adults who fall into the hypertensive category remarkably increase from 1.2 million to 5.2 million using the 2017 ACC/AHA. Despite the lowest awareness and treatment rates in this young group, their control rate was highest among all age groups. This implies that targeting younger groups brings about greater benefits for hypertension UHC programs and for the society through maintaining health among the working as well as the reproductive population of the country [35]. Given this potential benefit for Iran, the use of the 2017 ACC/AHA might also benefit other middle-income countries with similar population profiles [9].

Though adopting 2017 ACC/AHA led to a higher prevalence, yet not all adults falling into the hypertensive category were eligible for antihypertensive medications [5]. Based on the 2017 ACC/AHA, 37.2\% of Iranian adults aged $>25$ years (17.2 million adults) were eligible for pharmacologic therapy and based on JNC8 28.6\% (13.4 million adults) of them were [36]. With a minimum unit-cost of treatment around \$38 per person [37], pharmacologic therapy would annually cost $\$ 653$ million and $\$ 510$ million, respectively, under the 2017 ACC/AHA and JNC8 for all Iranian adults aged $>25$ years. Thus, the treatment costs incurred for pharmacotherapy by the health system under the 2017 ACC/AHA guideline was only marginally higher than the treatment costs under the JNC8.

We found that hypertension was very poorly controlled in Iran. Control is by nature a co-creational outcome. Both patient behaviour and an effective structure and process of care play roles in improving this outcome. Based on our findings, patient adherence to a healthy lifestyle and complementary insurance may improve the control rate [29, 30, 38]. We, however, call future research to examine other dimensions of effective structures and processes e.g. evidence-based care plan [39-41] and continuity of care $[42,43]$ to improve hypertension control.

This research had several limitations, including the challenge of causal inferences from cross-sectional data and potential misclassifications of covariates. We claim 
no causal relationships as making causal inferences from cross-sectional surveys is challenging. However, some of our criteria do help infer causal relationships; we relied on a compelling theoretical causal model with regards to examining the determining factors for the prevalence, awareness, treatment, and control of hypertension. This was followed by the associations observed between the focal variables as well as holding that the examined covariates and the causes logically precede these four outcomes [44].

We are also aware that there are potential misclassifications of covariates, particularly salt intake and smoking. We classified the participants based on $10 \mathrm{~g} /$ day cut-off for salt intake rather than the $5 \mathrm{~g} /$ day recommended cutoff point. We did so as a rather small number of our participants had salt intakes of less than $5 \mathrm{~g} /$ day.

With regards to our classification of smoking status, we classified never-smokers with former-smokers in the same group, which may affect the magnitude of effects this group has on the outcomes. The health outcomes of a former-smoker might still be influenced by his/her previous smoking history, which may offset the positive effects of the never-smoker on the health outcomes of interest [45]. Furthermore, the effect of smoking status might be incompletely represented by our data choices. We focused on cigarette only and other tobacco products were excluded from our analysis.

The external validity of our findings can be reasonably maintained by the multistage random proportional to size sampling employed. Participants were from all provinces (except one province) and from both urban and rural areas. Given this, the validity of inferences about the identified relationships might be, though not assuredly, maintained over variations in persons or times [46].

\section{Conclusions}

This manuscript applied a more progressive approach toward the measurement of prevalence, awareness, treatment, and control of hypertension services. The prevalence of hypertension markedly increased by the 2017 ACC/AHA guideline and at the same time awareness, treatment, and control sharply declined. Based on the 2017 ACC/AHA, more than half the adults aged $\geq 25$ years became hypertensive, which were mostly represented by the 25-34 age group. Since the control rate among younger adults was higher than among older adults, adopting the 2017 ACC/AHA guideline may benefit the young population of Iran and in the same way other middle-income countries with similar population profiles.

The new guideline lowers the cut-off value for diagnosis and puts a higher proportion of adults in the hypertensive category. Under this guideline, more individuals with high triglycerides, diabetes, and CVD events fell into a hypertensive category. Thus, by adopting the 2017 ACC/AHA a larger proportion of high-risk populations would be eligible for UHC programs. Yet, not all adults falling into a hypertensive category would need or receive antihypertensive medications; a large proportion of them can be treated through lifestyle modifications, based on the effect sizes reported in this study for LDL cholesterol, physical activity, and BMI.

Based on either guideline, Iran has improved the percentage of hypertension treatment; however, the awareness and particularly the control of hypertension remain a challenge. To improve the control rate, efforts should be made to improve both patient behaviour and the quality of healthcare services.

\section{Supplementary information}

Supplementary information accompanies this paper at https://doi.org/10. 1186/s12889-020-8450-1.

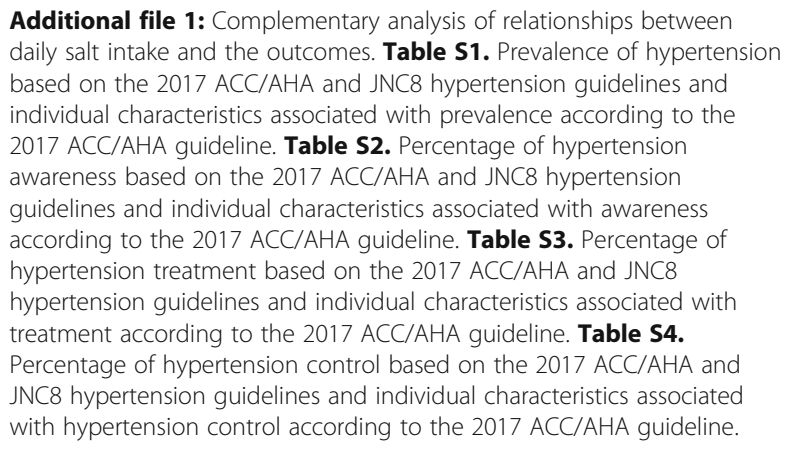

Additional file 1: Complementary analysis of relationships between daily salt intake and the outcomes. Table S1. Prevalence of hypertension based on the 2017 ACC/AHA and JNC8 hypertension guidelines and individual characteristics associated with prevalence according to the 2017 ACC/AHA guideline. Table S2. Percentage of hypertension awareness based on the 2017 ACC/AHA and JNC8 hypertension guidelines and individual characteristics associated with awareness according to the 2017 ACC/AHA guideline. Table S3. Percentage of hypertension treatment based on the 2017 ACC/AHA and JNC8 hypertension guidelines and individual characteristics associated with treatment according to the 2017 ACC/AHA guideline. Table S4. Percentage of hypertension control based on the 2017 ACC/AHA and JNC8 hypertension guidelines and individual characteristics associated with hypertension control according to the 2017 ACC/AHA guideline.

\section{Abbreviations}

2017 ACC/AHA: 2017 ACC/AHA/AAPA/ABC/ACPM/AGS/APhA/ASH/ASPC/ NMA/PCNA Guideline for the Prevention, Detection, Evaluation, and Management of High Blood Pressure in Adults; BMI: Body mass index; CVD: Cardiovascular disease; DBP: Diastolic blood pressure; DM: Diabetes mellitus; GPAQ: Global Physical Activity Questionnaire; HbA1c: Glycated haemoglobin (A1C); HTN: Hypertension; JNC8: The Eighth Joint National Committee on Prevention, Detection, Evaluation, and Treatment (JNC8) guidelines for the Management of High Blood Pressure in Adults; LDL: Lowdensity lipoprotein; MET: Metabolic equivalents; NIMAD: Iran National Institute for Medical Research Development; OR: Odds Ratio; SBP: Systolic blood pressure; SDG: Sustainable development goal; SES: Socioeconomic status; STEPS: World Health Organization (WHO) STEPwise approach to Surveillance; UHC: Universal Health Coverage

\section{Acknowledgements}

We wish to thank all organizations and individuals involved in the funding, planning, design, and data collection of the Iran STEPS 2016 study.

\section{Authors' contributions}

Conception and design of the study: MM1, MP, FF, BM. Statistical analysis: MP, MM1, BM. Manuscript preparation and revision: MM1, MP. Data acquisition and analysis: MM2, NA, MY, PM, SD, NR, RH, FP, ZM, MS, FR, SMS. All authors have read and approved all versions of the manuscript.

\section{Author's information}

Mahdi Mahdavi works as an assistant professor of health policy in Iran's National Institute of Health Research (NIHR), Tehran University of Medical Sciences (TUMS), Tehran, Iran. Before joining NIHR he was working as a PhD student and researcher at the Erasmus School of Health Policy and Management (ESHPM), Erasmus University Rotterdam, The Netherlands. 


\section{Funding}

The Iran STEPS 2016 study, that provided data for this research, was supported by Iran's National Institute of Health Research, Tehran University of Medical Sciences, under contract number 241/m/93/259.

\section{Availability of data and materials}

The datasets analysed during the current study are not publicly available due to national rules and regulations but are available from the corresponding author on reasonable request.

\section{Ethics approval and consent to participate}

The Iran STEPS 2016 study was evaluated and approved by the ethics committee of Iran's National Institute for Medical Research Development (NIMAD) under registration code 'IR.NIMAD.1394.032.' Before the interviews and measurements, all participants provided written informed consent.

\section{Consent for publication}

Not applicable.

\section{Competing interests}

The authors declare that they have no competing interests.

\section{Author details}

${ }^{1}$ National Institute of Health Research, Tehran University of Medical Sciences, Tehran, Iran. ${ }^{2}$ Erasmus School of Health Policy and Management, Erasmus University Rotterdam, Rotterdam, The Netherlands. ${ }^{3}$ Department of Epidemiology and Biostatistics, School of Public Health, Tehran University of Medical Sciences, Tehran, Iran. ${ }^{4}$ Non-Communicable Diseases Research Center, Endocrinology and Metabolism Population Sciences Institute, Tehran University of Medical Sciences, Tehran, Iran. ${ }^{5}$ Deputy of Research and Technology, Ministry of Health and Medical Education, Tehran, Iran. ${ }^{6}$ Endocrinology and Metabolism Research Center, Endocrinology and Metabolism Clinical Sciences Institute, Tehran University of Medical Sciences, Tehran, Iran. ${ }^{7}$ Reference Health Laboratory, Ministry of Health and Medical Education, Tehran, Iran. ${ }^{8}$ Diabetes Research Center, Endocrinology and Metabolism Clinical Sciences Institute, Tehran University of Medical Sciences, Tehran, Iran.

\section{Received: 5 August 2019 Accepted: 3 March 2020}

Published online: 17 March 2020

\section{References}

1. Zhou B, Bentham J, Di Cesare M, Bixby H, Danaei G, Cowan MJ, Paciorek CJ, Singh G, Hajifathalian K, Bennett JE. Worldwide trends in blood pressure from 1975 to 2015: a pooled analysis of 1479 population-based measurement studies with 19. 1 million participants. Lancet. 2017; 389(10064):37-55

2. Kearney PM, Whelton M, Reynolds K, Muntner P, Whelton PK, He J. Global burden of hypertension: analysis of worldwide data. Lancet. 2005;365(9455): 217-23.

3. Esteghamati A, Etemad K, Koohpayehzadeh J, Abbasi M, Meysamie A, Khajeh E, Asgari F, Noshad S, Rafei A, Mousavizadeh M, et al. Awareness, treatment and control of pre-hypertension, and hypertension among adults in Iran. Arch Iranian Med. 2016;19(7):456-64.

4. Whelton PK, Carey RM, Aronow WS, Casey DE, Collins KJ, Himmelfarb CD, DePalma SM, Gidding S, Jamerson KA, Jones DW. ACC/AHA/AAPA/ABC/ ACPM/AGS/APhA/ASH/ASPC/NMA/PCNA guideline for the prevention, detection, evaluation, and management of high blood pressure in adults: a report of the American College of Cardiology/American Heart Association task force on clinical practice guidelines. J Am Coll Cardiol. 2017;2017:24430.

5. Ihm SH, Bakris G, Sakuma I, Sohn IS, Koh KK. Controversies in the 2017 ACC/ AHA Hypertension Guidelines: Who Can Be Eligible for Treatments Under the New Guidelines? An Asian Perspective. Circ J. 2019;83(3):504-10.

6. James PA, Oparil S, Carter BL, Cushman WC, Dennison-Himmelfarb C, Handler J, Lackland DT, LeFevre ML, MacKenzie TD, Ogedegbe O. 2014 evidence-based guideline for the management of high blood pressure in adults: report from the panel members appointed to the eighth Joint National Committee (JNC 8). Jama. 2014;311(5):507-20.

7. Colantonio LD, Booth JN III, Bress AP, Whelton PK, Shimbo D, Levitan EB, Howard G, Safford MM, Muntner P. 2017 ACC/AHA blood pressure treatment guideline recommendations and cardiovascular risk. J Am Coll Cardiol. 2018;72(11):1187-97.

8. Wang Z, Hao G, Wang X, Chen Z, Zhang L, Zhang Z, Hu H, Weintraub WS, Gao R. For the China hypertension survey i: clinical outcomes and economic impact of the 2017 ACC/AHA guidelines on hypertension in China. J Clin Hypertens. 2019;21(8):1212-20.

9. Li D, Zeng X, Huang Y, Lei H, Li G, Zhang N, Huang W. Increased risk of hypertension in young adults in Southwest China: impact of the 2017 ACC/ AHA high blood pressure guideline. Curr Hypertens Rep. 2019;21(3):21.

10. Watkins DA. Implications of the 2017 ACC/AHA hypertension guideline for public health in Nepal. JAMA Netw Open. 2018;1(3):e180778.

11. Watkins DA. Implications of the 2017 ACC/AHA hypertension guideline for public health in NepalThe 2017 ACC/AHA hypertension guideline and public health in Nepallnvited commentary. JAMA Netw Open. 2018;1(3): e180778.

12. Organization WH. STEPS instruments for NCD risk factors (core and expanded version 1.4): the WHO STEPwise approach to Surveillance of noncommunicable diseases (STEPS). Geneva: World Health Organization; 2001.

13. Djalalinia S, Modirian M, Sheidaei A, Yoosefı M, Zokaiee H, Damirchilu B, Mahmoudi Z, Mahmoudi N, Hajipour MJ, Peykari N. Protocol design for large--scale cross--sectional studies of surveillance of risk factors of non-communicable diseases in Iran: STEPs 2016. Arch Iranian Med (AIM). 2017; 20(9):608-16.

14. Lu J, Lu Y, Wang X, Li X, Linderman GC, Wu C, Cheng X, Mu L, Zhang H, Liu J. Prevalence, awareness, treatment, and control of hypertension in China: data from 1. 7 million adults in a population-based screening study (China PEACE million persons project). Lancet. 2017;390(10112):2549-58.

15. Rutstein SO, Johnson K, MEASURE OM. The DHS wealth index: ORC macro, MEASURE DHS; 2004.

16. Culyer AJ: The Dictionary of Health Economics. The Dictionary of Health Economics, Second Edition 2010:xix.

17. Li G, Wang H, Wang K, Wang W, Dong F, Qian Y, Gong H, Hui C, Xu G, Li Y, et al. The association between smoking and blood pressure in men: a crosssectional study. BMC Public Health. 2017:17(1):797.

18. Agudo A, Joint F. Measuring intake of fruit and vegetables [electronic resource]: World Health Organization; 2005.

19. Tanaka T, Okamura T, Miura K, Kadowaki T, Ueshima H, Nakagawa H, Hashimoto T. A simple method to estimate populational 24-h urinary sodium and potassium excretion using a casual urine specimen. J Hum Hypertens. 2002;16(2):97.

20. Rezaei S, Mahmoudi Z, Sheidaei A, Aryan Z, Mahmoudi N, Gohari K, Yoosefi M, Hajipour MJ, Dilmaghani-Marand A, Soleimanzadehkhayat M. Salt intake among Iranian population: the first national report on salt intake in Iran. J Hypertens. 2018;36(12):2380-9.

21. Jette M, Sidney K, Blümchen G. Metabolic equivalents (METS) in exercise testing, exercise prescription, and evaluation of functional capacity. Clin Cardiol. 1990;13(8):555-65.

22. Grundy SM, Stone NJ, Bailey AL, Beam C, Birtcher KK, Blumenthal RS, Braun $\mathrm{LT}$, de Ferranti S, Faiella-Tommasino J, Forman DE. AHA/ACC/AACVPR/ AAPA/ABC/ACPM/ADA/AGS/APhA/ASPC/NLA/PCNA guideline on the management of blood cholesterol: a report of the American College of Cardiology/American Heart Association task force on clinical practice guidelines. J Am Coll Cardiol. 2018:2018:25709.

23. Association AD: 2. Classification and diagnosis of diabetes: standards of medical care in diabetes - 2018. Diabetes Care. 2018:41(Supplement 1):S13-27.

24. Khera R, Lu Y, Lu J, Saxena A, Nasir K, Jiang L, Krumholz HM. Impact of 2017 ACC/AHA guidelines on prevalence of hypertension and eligibility for antihypertensive treatment in United States and China: nationally representative cross sectional study. Bmj. 2018;362:k2357.

25. Muntner P, Carey RM, Gidding S, Jones DW, Taler SJ, Wright JT Jr, Whelton PK. Potential US population impact of the 2017 ACC/AHA high blood pressure guideline. Circulation. 2018;137(2):109-18.

26. Cifkova $R$, Fodor $G$, Wohlfahrt $P$. Changes in hypertension prevalence, awareness, treatment, and control in high-, middle-, and low-income countries: an update. Curr Hypertens Rep. 2016;18(8):62.

27. Dastan I, Erem A, Cetinkaya V. Awareness, treatment, control of hypertension, and associated factors: results from a Turkish national study. Clin Exp Hypertens. 2018;40(1):90-8.

28. Matar D, Frangieh AH, Abouassi S, Bteich F, Saleh A, Salame E, Kassab R, Azar RR. Prevalence, awareness, treatment, and control of hypertension in Lebanon. J Clin Hypertens. 2015;17(5):381-8. 
29. Abdul-Razak S, Daher AM, Ramli AS, Ariffin F, Mazapuspavina MY, Ambigga KS, Miskan M, Abdul-Hamid H, Mat-Nasir N, Nor-Ashikin MNK, et al. Prevalence, awareness, treatment, control and socio demographic determinants of hypertension in Malaysian adults. BMC Public Health. 2016; 16(1):351.

30. Ab Majid NL, Omar MA, Khoo YY, Mahadir Naidu B, Ling Miaw Yn J, Rodzlan Hasani WS, Mat Rifin H, Abd Hamid HA, Robert Lourdes TG, Mohd Yusoff MF. Prevalence, awareness, treatment and control of hypertension in the Malaysian population: findings from the National Health and morbidity survey 2006-2015. J Hum Hypertens. 2018;32(8-9):617-24.

31. Yusufali AM, Khatib R, Islam S, Alhabib KF, Bahonar A, Swidan HM, Khammash U, Alshamiri MQ, Rangarajan S, Yusuf S. Prevalence, awareness, treatment and control of hypertension in four Middle East countries. J Hypertens. 2017;35(7):1457-64.

32. Lee JH, Kim S-H, Kang S-H, Cho JH, Cho Y, Oh I-Y, Yoon C-H, Lee H-Y, Youn T-J, Chae I-H. Blood pressure control and cardiovascular outcomes: realworld implications of the 2017 ACC/AHA hypertension guideline. Sci Rep. 2018:8(1):13155

33. World Health Organization. Guideline: sodium intake for adults and children. World Health Organization. 2012. https://apps.who.int/iris/handle/1 0665/77985.

34. He FJ, Ma Y, Campbell NR, MacGregor GA, Cogswell ME, Cook NR. Formulas to estimate dietary sodium intake from spot urine alter sodium-mortality relationship. Hypertension. 2019:74(3):572-80.

35. Liu K, Colangelo LA, Daviglus ML, Goff DC, Pletcher M, Schreiner PJ, Sibley $\mathrm{CT}$, Burke GL, Post WS, Michos ED. Can antihypertensive treatment restore the risk of cardiovascular disease to ideal levels? The coronary artery risk development in young adults (CARDIA) study and the multi-ethnic study of atherosclerosis (MESA). J Am Heart Assoc. 2015;4(9):e002275.

36. Statistical Office of Iran. Selected Findings of the 2016 National Population and Housing Census. Statistical Office of Iran. 2019. https://www.amar.org.ir.

37. Brouwer ED, Watkins D, Olson Z, Goett J, Nugent R, Levin C. Provider costs for prevention and treatment of cardiovascular and related conditions in low-and middle-income countries: a systematic review. BMC Public Health. 2015;15(1):1183.

38. Mohammadi E. Evaluating impacts of the Iran's health transformation plan on the National Health Insurance System. National Institute of Health Research: Tehran; 2015.

39. Sadeghi-Ghyassi F, Mostafaie A, Hajebrahimi S, Ghojazadeh M, Mostafaie H. Ophthalmologist knowledge of evidence-based medicine and clinical practice guideline recommendations. Evidence Based Medicine. 2016;21(2): 49-54.

40. Nambisan P, Nambisan S. Models of consumer value cocreation in health care. Health Care Manag Rev. 2009;34(4):344-54.

41. Frow P, McColl-Kennedy JR, Payne A. Co-creation practices: their role in shaping a health care ecosystem. Ind Mark Manag. 2016;56:24-39.

42. Denyer D, Tranfield D, Van Aken JE. Developing design propositions through research synthesis. Organ Stud. 2008;29(3):393-413.

43. Mahdavi M, Vissers J, Elkhuizen S, Van Dijk M, Vanhala A, Karampli E, Faubel $\mathrm{R}$, Forte $\mathrm{P}$, Coroian $\mathrm{E}$, Van De Klundert J. The relationship between context, structure, and processes with outcomes of 6 regional diabetes networks in Europe. PLoS One. 2018;13(2):e0192599.

44. Van der Stede WA. A manipulationist view of causality in cross-sectional survey research. Acc Organ Soc. 2014;39(7):567-74.

45. Copeland KT, Checkoway H, McMichael AJ, Holbrook RH. Bias due to misclassification in the estimation of relative risk. Am J Epidemiol. 1977; 105(5):488-95.

46. Ferguson L. External validity, generalizability, and knowledge utilization. J Nurs Scholarsh. 2004:36(1):16-22.

\section{Publisher's Note}

Springer Nature remains neutral with regard to jurisdictional claims in published maps and institutional affiliations.

Ready to submit your research? Choose BMC and benefit from:

- fast, convenient online submission

- thorough peer review by experienced researchers in your field

- rapid publication on acceptance

- support for research data, including large and complex data types

- gold Open Access which fosters wider collaboration and increased citations

- maximum visibility for your research: over $100 \mathrm{M}$ website views per year

At BMC, research is always in progress.

Learn more biomedcentral.com/submissions 